\title{
A New Research on the Modern Distance Education Model Based on Wechat Official Accounts
}

\author{
Hai Zeng, Yingzhen Tan \\ School of Teacher Distance Training, Guangzhou Open University, \\ Guangzhou City, Guangdong Province, 510091
}

\begin{abstract}
The continuous development of information technology and new media, and the rapid popularization of mobile devices have injected new elements into the modern distance open education model. As a mobile application software with functions of communication, social contact and platform, WeChat with its powerful functions meets the needs of distance education which provides learning content without limitations of time and space. Based on the author's learning and practical experience, this paper firstly analyzed the applicability of the Wechat platform in distance education and then proposed the application strategies of the WeChat public platform in modern distance education.

Keywords: Wechat official account; Distance education; Applicability; Feasibility; Application strategies

\section{Introduction}

The number of modern distance education students has increased extensively and outdistances the number of students with correspondence, self-examination and other forms of adult education. Obviously, modern distance education has become the most important form for adults to improve their education and gain knowledge. At the same time, China's distance education practice of Zhang Jianwei in Tsinghua University shows that the biggest difficulty encountered by distance education students is the lack of opportunities for communication with teachers[1]. Bai Hao in Shaanxi Normal University believes that the increasingly
\end{abstract}


mature WeChat public platform can achieve the information exchanges between teachers and students in groups and it will have a broad application prospect in education.

\section{The Applicability of Wechat Public Platform in Distance Education}

\subsection{The platform model is suitable for distance open education students}

Distance open education students basically include serving staff who have their own business and family with many social activities. There are various things that distract their attention and it is not realistic for them to spend longer time to learn. Therefore, it is necessary for them to make full use of spare time in daily work and life to learn[2]. For example, adults can learn when they wait for the bus, go home after the work, line up in banks, take a rest in shopping and do housework. There are some big differences for adult learners in the learning background and learning ability and each person has different learning styles and habits. WeChat platform-assisted learning requires little in learning motivation intensity. Learners just have a marginal input or non-continuous attention and designers continue to stimulate learners to learn and give them continuous feedback to achieve the results.

\subsection{It is easier for distance open education students to accept the platform} resource design

When teachers design learning resources, they should carefully design resources according to the content, the mastery degree and the psychological characteristics of adult students. For example, teachers should consider what can be presented in text form, what is appropriate for presentation in audio or video or which needs to be expressed in multiple forms. Therefore, the learning resources obtained by adult learners are highly targeted both in terms of content and form, so as to enable students to acquire knowledge effectively in a relatively short period. In the arrangement of the overall content, teachers not only use resources closely related to the course learning, but also should make use of various information and articles which are related to the practical application and operation of the course and attract students' attention to make students learn in an easy and happy environment[3].

\subsection{The platform meet the needs of the self-learning in distance open education}

The idea of modern distance open education is to provide students with rich teaching resources on the network platform to carry out self-learning. The limited time of the traditional face-to-face teaching in open education and the diversity of students' social roles determine that most of the learning needs to be done by 
students themselves. Therefore, how to effectively carry out self-learning is the key. The characteristics of the public platform meet the needs of students to effectively carry out the self-learning. On one hand, the key and difficult knowledge in the classroom teaching is presented in the forms of small modules, which is easy for students to learn and master; on the other hand, the platform teaching is based on hand mobile devices and its convenience provides a strong support for the learning without limitations of time and space. With the deepening impact of mobile devices on daily life, the introduction of mobile network teaching environment to course teaching activities can meet the needs of learners' self-learning and improve the teaching model under the background of the rapid development of information technology[4].

\section{The Application Strategies of the WeChat Public Platform in Modern Distance Education}

\subsection{To establish a convenient WeChat public platform working mechanism}

The public platform should correspond the virtual identity of the user in Wechat to the real identity in the distance education center. When students access the Wechat public platform, the system can automatically define students' identity; students can obtain the access right of the distance education without logging in the platform. To achieve the docking between WeChat and users' identities in distance education center, distance education center can create a WeChat public platform working mechanism. The specific implementation method is the following: when students use WeChat service of the distance education center for the first time, WeChat official service will send students' Open ID to the WeChat server of distance education center. When the distance education center server receives the ID, it will return a requirement for students' school numbers and passwords. When students fill these and send them to the server of the distance education center to approve the identity. Once the certification is passed, the corresponding relationship between students' school number and their Open ID will be recorded into the distance education center database. Ultimately, students' Wechat accounts will bind their school numbers. In this way, when students visit again, the public platform can immediately determine the true identity of students in the distance education center and then automatically provide them access to the platform.

\subsection{To apply the WeChat public platform to the modern distance teaching}

Teachers may use micro courses or multimedia courseware to make exquisite teaching design and push the design to students' mobile terminals by virtue of WeChat public platform, so that students can make use of their spare time to learn. The account administrators can add page links of course knowledge points, so that students can subscribe to relevant information and grasp the key and difficult points of this course[5]. With the use of WeChat public platform, 
teachers can also carry out online homework counseling, question discussion, video playing of micro-video, message counseling and other activities. For example, by virtue of the message pushing function of WeChat public platform, teachers present texts, pictures, videos and other materials to students in the material management option. In addition, WeChat public platform has the function of the auto-response to the keywords. In other words, students can input keywords pushed by WeChat public account and can accurately find relevant knowledge with replying to the corresponding keyword. Certainly, because of the restriction of the number of pushing messages in current WeChat public platform, the pushing learning content is still relatively limited. For example, the size of the picture message is limited within $2 \mathrm{M}$ and the video can not exceed 1 minute. Therefore, the promotion and application of WeChat public platform in distance teaching remains to be developed.

\subsection{To apply the WeChat public platform to the management}

Essentially, Wechat public platform is a one to many transmission model, but the information is not one-way flow, so that users can also feed back texts, pictures, voices, micro videos and location information. Therefore, the modern distance education center can use WeChat public platform to carry out a series of management work. As a supplementary means of teaching services, Wechat public platform can connect notice management with information dissemination of the management platform of the distance education center to send the announcement and other information automatically to users[6]. On this basis, the distance education center can announce the latest news, contact information of educational administration personnel and other important information, and students can also query the individual academic records of all courses, the examination arrangements of this semester and online counseling course schedule. In addition, the distance education center can also use WeChat public platform to push information about the characteristics of their academic education, enrollment brochures and other information to the community, so as to promote the smooth implementation of the recruitment and propaganda work. Certainly, if the distance education center only focuses on the publicity of enrollment advertisement and provides students with little information, the WeChat public platform is not significant for the teaching[7]. The custom response content in the official account management platform is not what the students need sometimes, so the account manager should add comment function and answer students' questions in a targeted way, so as to truly realize the effective communication between students and the management platform.

\section{Conclusion}

Smart mobile terminals are easy to carry and operate, but their screens are small, which is not suitable for people to watch it for a long time. The presented content resources should be relaxing with short text. Video resources should be mainly 
micro classes within 8 minutes, which is easy to watch. If students want to complete the course systematically, they can participate in face-to-face lessons or $\log$ in to the corresponding learning platform. Moreover, the education should focus on the timeliness of communication platform. One to one communication between teachers and students on WeChat platform can only be achieved through the PC, which affects the timeliness of communication to some extent. The best way is that teachers and class students become WeChat friends, so that students can communicate with teachers at any time .

WeChat platform has many powerful functions and its application to the teaching facilitates the development of informal learning. However, it is only a learning tool, so we can not rely on WeChat to solve all the problems in teaching and the traditional teaching model is irreplaceable. In the premise of traditional teaching, teachers should give full play to the advantages of WeChat and apply it to preclass and after-school teaching links to make up the shortcomings of face-to-face teaching. Although the mixing teaching with the Wechat platform achieves some results, there are still some problems that need to be further improved. In the future practice, teachers need to continue to explore and improve the model in content and technology to improve the mixing teaching model based on WeChat platform.

\section{Acknowledgement}

The research was reported by the fallowing items:

Teachers' Continuing Education Innovation of Academic Team in Guangzhou City(2014-14-13C13).

Study on the construction and application of open education curriculum supermarket and credit bank system under the background of lifelong education in Guangdong province education research project of the year of 12th FiveYear(2011TJK180).

The research and application of the construction and demonstration project of continuing education system in higher education institutions of Guangdong province([2012] 9).

\section{References}

[1] Yuan Baoling. A Study on the Exploration and Practice of the Microcurriculum Development Based on Wechat Official Accounts in Higher Vocational Colleges. Sichuan Vocational and Technical College, (04), pp.157159.

[2] Chang Hanjie. A Study on the Application of WeChat Platform in Distance Teaching. Journal of Inner Mongolia Radio and TV University, (04), pp.79-80, 2016. 
[3] Chen Xiaoqin. A Study on the Construction of Cadre Mobile Learning Model Based on WeChat Public Platform. Journalism and Communication, (24), pp.7576, 2015.

[4] Tang Guangyuan. An Applied Research of the WeChat Public Platform to the Distance Education in the Tibet Rural Areas. Tibet Journal of Agricultural Science, (04), pp.46-48, 2015.

[5] Cai Lifeng. An Applied Research of WeChat Public Platform to the Modern Distance Education. China Education Information, (17), pp.18-19, 2015.

[6] Song ChenFei, Cai Jiandong. A Study on the Strategies of the Improvement of the Application of WeChat Public Platform to Mobile Learning. Digital Education, (03), pp.36-41, 2015.

[7] Xu Meidan, Lan Guoshuai, Zhang Yichun, Meng Zhaokun and Zhang Hang. A Study on the Construction of the Mixing Learning Model Based on WeChat Public Platform. Distance Education in China, (04), pp.36-42, 2015. 